\title{
INFLATION DIFFERENTIALS ACROSS REGIONS IN TURKEY
}

Hasan Engin Duran

\section{Abstract}

The aim of the present article is to analyze the convergence of regional inflation rates in Turkey from 2004 to 2015 by adopting sigma convergence and distribution dynamics approaches. The outcomes of our research can be summarized in two groups. First, inflation disparities tend to decline over time, especially during the post-crisis period after 2010. Hence, the aggregate price stabilization and disinflation process in Turkey is coupled with convergence in inflation rates across regions. Second, in addition to the findings in the literature, we find that regions change their relative inflation rate positions quite often. This indicates that regional inflation behavior is random and non-structural, as the relatively high and low inflationary places tend to change their quintiles frequently. The results imply several policy suggestions. First, achieving inflation convergence is a harder task than initially understood, as it seems to show random behavior. Second, trade integration can be an option to foster regional price convergence.

Keywords: Inflation convergence, regional inflation, distribution dynamics, Kernel density, Panel Unit Root

JEL Codes: $R 1, E 3, E 5$,

\section{INTRODUCTION}

In the literature on monetary economics, the dispersion of inflation rates across the regions of a country may constitute severe policy distortions (Weber and Beck 2005). Firstly, if inflation rates differ largely between regions, monetary policy can hardly satisfy the needs of all regions equally (Weber and Beck 2005; Mundel 1961; Weyerstrass et al. 2011), such that places which experience high inflation rates naturally require a contractionary monetary policy, while those which experience low inflation need rather an expansionary monetary stance (Weber and Beck 2005). Furthermore, inflation differentials are likely to create regional dispersion in the real interest rates, which are likely to induce differential effects on local economic growth (YIlmazkuday 2013). Another policy problem regards the specific case of Turkey, for which regional integration is seen as a necessity prior to EU accession (Yeşilyurt and Elhorst 2014). For these reasons, convergence across regional inflation rates is politically a crucial matter.

With regard to the literature on convergence, existing studies mostly rely on Neo-classical growth theory and its empirical predictions (i.e. Solow 1956; Barro and Sala-i Martin 1992; Rey and Montouri 1999). Within this stream, much of the attention has been devoted to testing the tendency of regional incomes or total factor productivity to converge. However, far little attention has been paid to the issue of inflation convergence (for some examples see Cechetti, Mark

\section{Hasan Engin Duran, $\mathrm{PhD}$}

Izmir Institute of Technology

City and Regional Planning Department

E-mail: enginduran@iyte.edu.tr 
and Sonora (2002); Weber and Beck (2005); Yesilyurt (2014).

Methodologies that have been used so far in order to test inflation convergence are quite scant in the literature. Indeed, most of them rely on a class of Panel Unit root tests (see for some examples, Breitung and Das 2003; Breitung 2000; Chang 2002; 2004; Levin, Lin and Chu 2002; Im et al. 2003) which are known as useful longitudinal tools in testing whether relative rates of inflation follow a stationary process and converge to an equilibrium.

However, the major drawback of such a methodology is that it gives no information about intra-distributional dynamics, the shape of the inflation distribution and its evolution over time (Quah 1993a; Magrini 2009). However, the distribution dynamics approach is more informative in that sense (Magrini 2009). It provides information on both understanding the convergence trend since one can observe the evolution of the shape of relative inflation distribution, and also it provides information on the mobility of regions within the distribution (Magrini 2009).

The aim of the present study is to analyze the convergence of regional inflation rates in Turkey from 2004 to 2015 by adopting the sigma convergence and distribution dynamics approaches, namely, simple discrete time Markovian chains (Asmussen 2003). The regional and aggregate consumer price index and inflation dataset are obtained from the Central Bank of Turkey (TCMB), Turkish Statistical Institute (Turkstat) and Ministry of Development.

Turkey is an interesting case study as it includes large socio-economic and territorial imbalances (Yıldırım, Öcal and Özyıldırım 2009; Gezici and Hewings 2007). There are differentials in inflation rates across provinces (Yeşilyurt and Elhorst 2014). Moreover, Turkey has experienced a rapid stabilization and disinflation period over the last three decades, such that the annual inflation rate has declined from about $116 \%$ (in 1994) to $8 \%$ (in 2015). However, the distributional aspect of inflation within the country has not yet been adequately studied. This makes our analysis more interesting per se.

The paper is organized in the following way. In Section 2, a summary of the related literature is provided. Section 3 is devoted to empirical analysis composed of two parts. In 3.1, we implement descriptive and exploratory analyses which document the stylized facts on both regional and national inflation in Turkey. In 3.2, we perform a formal convergence analysis by using first Panel Unit Root tests and then apply a distribution dynamics methodology. Finally, Section 4 is devoted to concluding remarks.

\section{LITERATURE REVIEW}

In the existing literature, the issue of inflation convergence is thoroughly and heatedly debated in a number of theoretical and empirical studies.

From a theoretical point of view, economic drivers of inflation convergence/divergence are extensively discussed. The intensity of the traded-goods sector and trade integration among countries are referred to as the major reasons fostering convergence in price movements (Yllmazkuday 2013). This is consistent with the Balassa-Samuelson effect, which explains why prices are higher and non-convergent in the nontraded sector (Balassa 1964; Samuelson 1964; Tunay and Silpagar 2007). In other words, it implies that the intensity of trade linkages across regions hamper arbitrage-driven profit possibilities and enhance price equilibration (Yılmazkuday 2013). However, there are some crucial distinctions between the BalassaSamuelson effect and the Baumol-Bowen effect and these arguments are examined in several papers (Mihaljek and Klau 2004; 2008). The main distinction regards the fact that in the services sector productivity growth is likely to be slower than in the capital-intensive goods sector. Therefore, prices in the services sector are expected to be higher and non-convergent. While services are in general non-tradable, some are in fact tradable. Hence, this point is crucial but has not been taken into account in the Balassa-Samuelson effect (Baumol and Bowen 1966)

One of the other reasons why prices do not converge might be related to rigidities in wages or exchange rates (Becker 2011). Any factor that prevents the nominal exchange rates and wages to adjust in response to an economic shock can be a reason for inflation differentials (Becker 2011). Finally, asymmetric economic shocks that can change the demand/ supply conditions in different countries and can cause dispersed price movements (Weber 2004; Tunay and Silpagar 2007).

On empirical grounds, the vast majority of studies point to the tendency towards declining inflation disparities either at the cross-national or cross-regional level.

With regard to the cross-national examples, there is, one the one hand, a number of studies that address EU (European Union) countries. For instance, Siklos and Wohar (1997), Mentz and Sebastian (2003), Rogers, Hufbauer and Wada (2001), Kocenda and Papell (1997), Beck and Weber (2001), Holmes (2002), Beck, Hubrich and Marcellino (2006) and Busetti et al. (2007) are among the studies which find evidence in favor of inflation convergence within the EU. This finding is also supported theoretically, as it is consistent with the conventional view that increased trade 
integration, financial linkages and migration, as well as the introduction of a common monetary system, promote price convergence (Rogers 2007).

On the other hand, there is a strand of studies focusing on inflation differentials across the regions of a country. Beck, Hubrich and Marcellino (2006), for instance, focus on the regions of $6 \mathrm{EU}$ member states and 11 U.S. metropolitan areas over the period 19952004. They report evidence suggesting two facts. First, compared to early 1990 s, inflation dispersion has lowered within the EU, and therefore a convergence trend has been observed. Second, inflation dispersion within the U.S has been found to be lower compared to the EU.

In another study, Cechetti, Mark and Sonora (2002) investigate whether inflation rates in 19 major U.S. cities tend to converge over the period 1918-1995 and report evidence in favor of convergence. Weber and Beck (2005) examine the convergence process across 24 Metropolitan areas in U.S. between 1980-2002, across 12 provinces in Canada between 1980 and 2002, and across 47 prefectures in Japan between 1985 and 2000. The main result of the paper is that regional dispersion of inflation rates has been found to be lowest in Japan and at considerable levels in U.S. and Canada. However, the disparities tend to decline in the U.S.-Canada sample, whereas it tends to increase in Japan.

From a methodological point of view, sigma and beta convergence models are typically used in income and inflation convergence studies (see Barro and Sala-I-Martin 1992 and Rey and Montouri 1999 for detailed explanations). In beta convergence, usually a regression analysis is pursued. Typically, initial incomes of the regions are regressed on the growth rates of regions over the period of analysis, with the possibility of the inclusion of control variables. In sigma convergence, an index that represents the level of regional inequalities in each year is calculated. This index is then analyzed using unit root tests to understand whether it exhibits a downward trend, which would mean convergence among regions. To investigate the inflation convergence, we use the sigma convergence and distribution dynamics approach, as it is more convenient for time series studies with a large cross-sectional dimension.

Although extensive literature exists on other countries, studies in this field are quite limited for Turkey. Initially, Tunay and Silpagar (2007) examined inflation convergence across geographical regions for the period 1994-2004 using monthly regional CPI (Consumer Price Index) data. They adopt a widely accepted Panel Unit Root test in their study. Specifically, they use the type of test developed by Breitung and Das (2003),
Levin, Lin and Chu (2002) and Im, Pesaran and Shin (2003). In all tests, they reject the null hypothesis of non-stationary regional rates of inflation, which indicates evidence of convergence. Moreover, using panel regressions, they show that price movements in a region spill over to neighbouring regions significantly.

Similarly, Akdi and Sahin (2007) find a sectoral inflation convergence pattern over the period 19882007. More recently, Yılmazkuday (2013) investigated whether inflation dispersion has structurally changed after the introduction of "inflation targeting" policy of the Central Bank in January 2002. He employed monthly CPI data for 10 sub-groups of products and 7 geographical regions over the period 1994-2004. He found that both the mean and the standard deviation of inflation rates declined following an inflation targeting policy. Moreover, it is also claimed that the adoption of flexible exchange rate in 2001 (February) is another reason for such a decline.

Finally, Yeşilyurt (2014) adopts monthly CPI data for 26 NUTS-2 regions over the period 2004-2011. She uses pairwise unit root test which had been introduced initially by Pesaran (2007), and incorporates the structural breaks in series by using a technique developed by Zivot and Andrews (1992). As an outcome, she rejects the null hypothesis of no convergence, and therefore finds evidence in favor of declining inflation disparities.

Although existing studies on Turkey reflect, more or less, the same result, our contribution to the debate will be methodological. Technically, studies in the literature mostly focus either on panel unit root tests or traditional convergence methodologies such as $\beta$ or $\sigma$ convergence. Both are criticized due to biases in regression techniques and unreliable outcomes (as in Galton's Fallacy explained in Quah 1993b). Moreover, these conventional methods are inadequate in terms of providing more information on the shape of inflation distribution, its evolution over time and the mobility of regions within the distribution (Magrini 2009). Specifically, a distribution dynamics approach estimates the empirical distribution of regional incomes (i.e. Kernel density estimates), their evolution over time and their ergodic distribution (Magrini 2009). In this way, the researcher is able to observe whether the distribution tends to take a more homogenous and uni-modal form, which indicates a decline in income disparities, or a bi-modal and more heterogeneous form, which indicates an increase in disparities. Moreover, using discrete time Markov transition matrices, the researcher is able to observe if the mobility of regions within the distribution is high or low.

Thus, we pursue such a methodology in this paper by implementing an empirical analysis in the next section. 


\section{EMPIRICAL ANALYSES}

\subsection{Descriptive and Exploratory Analysis}

The initial step in our analysis is to describe the historical evolution of the inflation rate in Turkey. The data declared by Turkstat (Turkish Statistical Institute) reveal that percentage changes in $\mathrm{CPI}$ at the national level from 1983 to 2010 indicate an increasing trend of inflation until the mid-1990s and a sharp decline afterwards, hitting levels of about 7-8\% after 2005.

Rapid changes in inflation rates deserve a few words on their political and historical evolution. Over the last decades, high inflation has been a major policy concern of the government (Yeşilyurt 2014; Yeşilyurt and Elhorst 2014). Following the military revolution and economic crisis in 1980, a set of policies aiming at both disciplining fiscal deficits and trade liberalization were applied. However, the outcomes were not successful in lowering inflation. Thus, in 1994 the national inflation rate reached a peak of about $116 \%$. Public sector deficits, the devaluation of Turkish liras against foreign currencies, the consequent increased prices of imported goods, political instability and the first Gulf War have been put forward as the major reasons for the hyperinflation (Yeşilyurt 2014; Yeşilyurt and Elhorst 2014).

On 5 April 1994, a new economic program was declared. Although inflation rates were reduced considerably, in 1999 an economic crisis and the earthquake hit the supply side of the economy and caused another pressure on prices (Yeşilyurt 2014; Yeşilyurt and Elhorst 2014). After the economic crisis in 2001, successful years in terms of inflation began (Yeşilyurt 2014; Yeşilyurt and Elhorst 2014). Tight fiscal and monetary policies and budget discipline played a major role in this process (Yeşilyurt 2014; Yeşilyurt and Elhorst 2014). An implicit inflation targeting policy was implemented during the years 2002-2005 (Yeşilyurt 2014). After 2006, explicit inflation targeting was applied (Yeşilyurt 2014). In 2005, increases in oil prices and a supply shock caused an increase in price (Yeşilyurt 2014). During the global economic crisis of 2008-2009, a rise in interest rates led to lower pressures on prices (Yeşilyurt 2014). Finally, after 2010 a more stable price index was observed.

With regard to the regional dimension of inflation, several stylized facts can be identified. For that purpose, we document the geographical distribution of inflation rates among regions. Figure 1 below illustrates the percentage changes in CPI for 26 Nuts-2 regions over the period from January 2003 to March 2015.

There is an important level of cross-regional variation in inflation rates. The darkest color represents the regions which have had the highest inflation rates, while the lightest color represents the regions which have had the lowest rates. The regions which have had the highest inflation are TR22 (Çanakkale-Balıkesir), TR51 (Ankara) and TR10 (İstanbul), which have had cumulative interest rates of $183 \%, 179 \%$ and $178 \%$,

Figure 1: Geographical Distribution of Inflation Rates

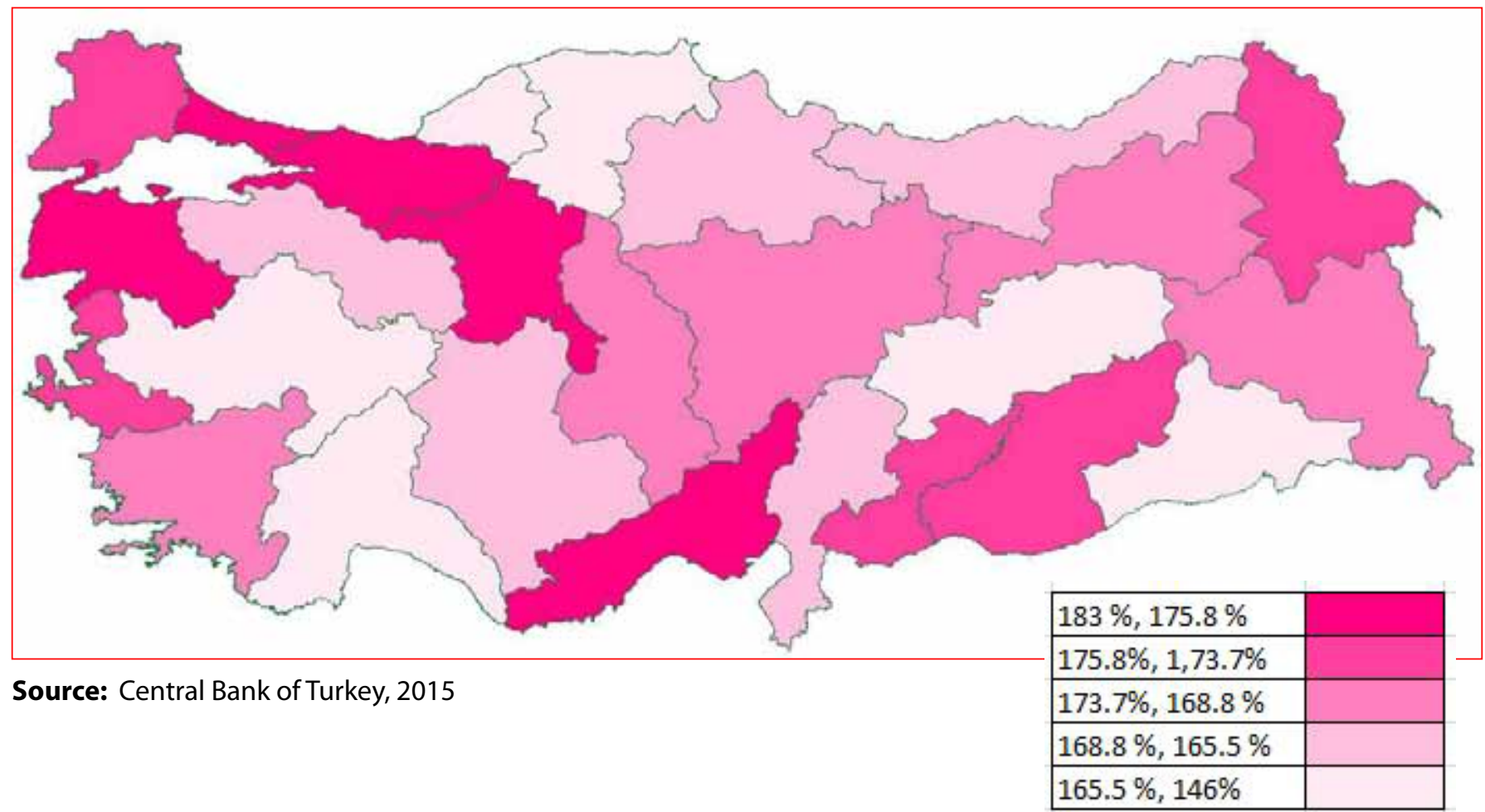


respectively, over the last 12 years. The regions which have had lowest inflation are TRC3 (MardinBatmanŞırnak-Siirt), TR61 (Antalya-Isparta-Burdur) and TR81 (Zonguldak-Karabük-Bartın), which have had inflation rates of $146 \%, 158 \%$ and $162 \%$, respectively.

High inflation is generally observed around the Marmara region. There are several possible reasons why this is the case. First, since it is an industrial base, it attracts inward migration, which makes demand grow faster than in other regions. Indeed, wages are most probably higher, which causes demand-pull inflation (Barth and Bennet 1975). Apart from the demand side, supply side factors are also quite important (Barth and Bennet 1975), such that intermediate goods are known to be intensively imported in this region. Hence, any depreciation in the Turkish lira against foreign currencies is likely to increase the cost of inputs considerably (capital goods, raw materials etc.), leading to cost-push inflation (Barth and Bennet 1975).

Looking at the general picture, however, we do not observe a distinct geographical pattern in inflation. The commonly found east/west dualism in economic development is not observed in inflation. The visual inspection of the map gives us the idea that changes in price levels are rather randomly distributed within the country. This makes it even harder to explain the phenomenon.

Anyhow, in order to confirm this statistically and to understand whether or not the inflation rates are distributed in a spatially correlated manner, we test spatial dependence using Moran l's test, which was initially introduced by Moran (1950) and is widely used in the empirical literature (Rey, 2001). The test takes the following form (Rey 2001) ${ }^{1}$ :

$$
I=\frac{n}{\sum_{i} \sum_{j} w_{i, j}} \frac{\sum_{i} \sum_{j}\left(X_{i}-\bar{X}\right)\left(X_{j}-\bar{X}\right)}{\sum_{i}\left(X_{i}-\bar{X}\right)^{2}}
$$

where $x$ is a variable of interest, $\bar{X}_{i}$ is its cross-sectional mean, and $w$ is a spatial weight matrix. It is in the form of a raw standardized inverse distance matrix. Hence, the nearest neighbors get a high weight in this scheme.

A positive and significant I would indicate a positive spatial correlation, which means that regions which have similar inflation rates locate nearby. However, what we observe from our test is totally different. The estimated Moran I's statistic is negative as well as insignificant (Table 1). One may then conclude that inflation rates in Turkey seem to follow a random geographical distribution.
Table 1: Moran I's Test Results

\begin{tabular}{|l|l|}
\hline Test Statistics & Values \\
\hline Moran I's statistics & $-0,053$ \\
\hline Expectation & $-0,04$ \\
\hline Variance & 0,002 \\
\hline P-Value & 0,61 \\
\hline
\end{tabular}

Note: raw standardized inverse matrix has been used.

Overall, the cross-regional differentials in inflation cannot be neglected, as it ranges over a large interval (between 146\% and 183\%). Moreover, the geographical distribution of inflation is quite random.

The descriptive analysis, however, does not provide any information about inflation convergence. Therefore, we pursue this analysis in the next section.

\subsection{Convergence Analysis}

The evolution of inflation disparities is analyzed in the present section. Initially, we present in Figure 2 the cross-sectional standard deviation (SD) of regional yearly inflation rates over time (from January 2003 to March 2015). Regional Inflation rate in this case has been defined as the first differences of 12-month moving CPI (in natural logarithms):

$$
\pi_{t}=\ln \left(C P I_{t}\right)-\ln \left(C P I_{t-12}\right)
$$

where $t$ indicates the months.

Figure 2: Cross sectional SD of Inflation Rates,

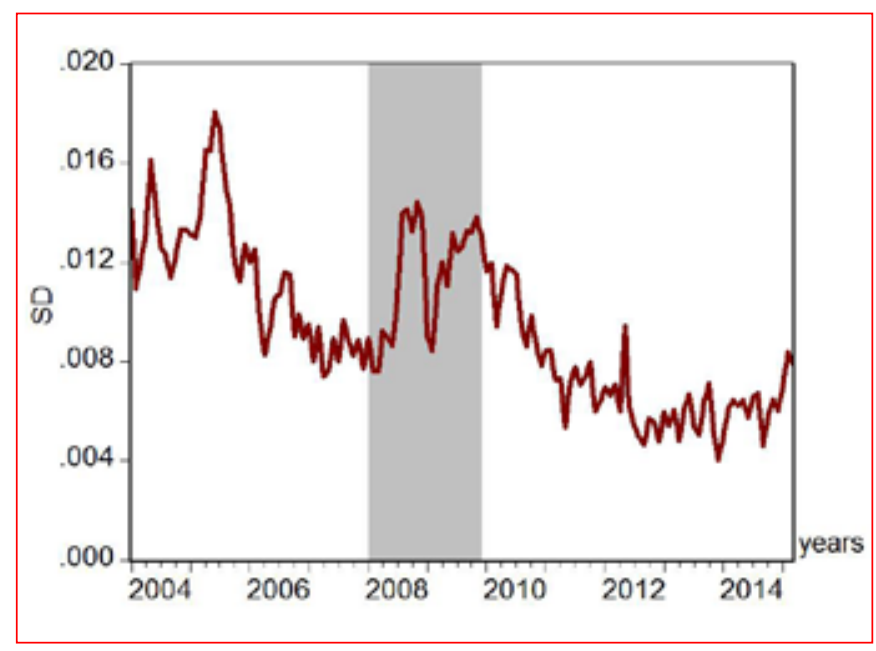

Source: Central Bank of Turkey, 2015

\footnotetext{
1 The Moran I test's formula is obtained from Rey (2001).
} 
Looking at the SD of regional inflation rates, it is immediate to note that a tendency towards a decline in dispersion is obvious. In other words, regions tend to become more equal in their inflation rates, indicating preliminary evidence of inflation convergence.

The only exception that does not fit this trend is the period of the global economic crisis during 2008 and 2009, which is shaded in grey. During the financial crisis, regional price levels increased arbitrarily and this caused an inflation differential.

For three important periods, pre-crisis, during the crisis and post-crisis, we document the yearly inflation rates of regions along with their cross-sectional means and standard deviations. We report the calculations in Table 2.

In the period of 2004-2007, inflation rates ranged between $7.18 \%$ and $10 \%$, whereas they ranged between $7.11 \%$ and $9.57 \%$ in the period of $2008-2009$ and between $6.99 \%$ and $8.02 \%$ in the period of 2010 2014. Hence, the range tends to narrow, indicating a sign of declining inflation differentials across regions. Moreover, the regions tend to experience lower inflation rates, as the mean of inflation is $8.80 \%$ in the first period, $8.42 \%$ in the second period and $7.77 \%$ in the last period. Furthermore, the declining disparities and inflation convergence hypothesis is supported by the standard deviation values, which decline from 0.71 to 0.39 over these years.

In order to provide supportive statistical evidence on convergence, we apply a unit root test on regional inflation rates shown in Figure 3. Specifically, the test is developed by Levin, Lin and Chu (2002) (LLC) and is very widely used in this field. The test relies on the following ADF (Augmented Dickey Fuller) regression (Dickey and Fuller 1979) 2:

$$
\Delta x_{i, t}=\alpha x_{i, t-1}+\sum_{j=1}^{\rho_{j}} \beta_{i, j} \Delta x_{i, t-j}+Y^{\prime}{ }_{i, t} \delta+e_{i, t}
$$

where $x$ is the variable of interest. In our case, $x$ represents relative annual regional inflation rates. Specifically, it is the cross-sectional de-meaned $\pi_{t}$ where $\overline{\pi_{t}}$ is the cross-sectional average of inflation rates at time $\mathrm{t}$ :

$$
x_{i, t}=\pi_{i, t}-\overline{\pi_{t}}
$$

The sign and significance of $\alpha$ parameter, which is a common coefficient for all cross-sectional units, is the

2 The panel unit root specification and ADF regression are obtained from Eviews 6 program's user guide.

The empirical analysis in this paper is implemented using Eviews 6, Eviews 4, Excel, R 3.12 software programs
Table 2: Descriptive statistics on yearly inflation rates of regions

\begin{tabular}{|c|c|c|c|}
\hline Regions & $2004-2007$ & $2008-2009$ & $2010-2014$ \\
\hline TR10 & 9,81 & 9,23 & 6,99 \\
\hline TR21 & 9,76 & 7,11 & 7,80 \\
\hline TR22 & 9,41 & 8,70 & 7,84 \\
\hline TR31 & 9,42 & 7,58 & 7,71 \\
\hline TR32 & 9,53 & 7,58 & 7,56 \\
\hline TR33 & 8,37 & 8,13 & 7,69 \\
\hline TR41 & 9,64 & 8,05 & 7,18 \\
\hline TR42 & 10,00 & 8,69 & 7,21 \\
\hline TR51 & 9,76 & 8,76 & 7,39 \\
\hline TR52 & 9,14 & 7,72 & 7,72 \\
\hline TR61 & 8,61 & 7,43 & 7,38 \\
\hline TR62 & 9,23 & 8,26 & 8,02 \\
\hline TR63 & 8,42 & 8,33 & 7,78 \\
\hline TR71 & 8,44 & 8,69 & 8,29 \\
\hline TR72 & 8,68 & 8,40 & 7,99 \\
\hline TR81 & 8,39 & 9,14 & 7,22 \\
\hline TR82 & 8,37 & 8,24 & 7,61 \\
\hline TR83 & 8,83 & 8,20 & 7,61 \\
\hline TR90 & 8,35 & 8,98 & 7,76 \\
\hline TRA1 & 8,74 & 8,89 & 7,98 \\
\hline TRA2 & 8,26 & 9,57 & 8,07 \\
\hline TRB1 & 8,02 & 8,55 & 8,22 \\
\hline TRB2 & 8,36 & 9,40 & 7,79 \\
\hline TRC1 & 7,78 & 9,00 & 8,45 \\
\hline TRC2 & 8,27 & 8,19 & 8,43 \\
\hline TRC3 & 7,18 & 8,07 & 7,28 \\
\hline Mean & 8,80 & 8,42 & 7,73 \\
\hline SD & 0,71 & 0,63 & 0,39 \\
\hline
\end{tabular}

Source: Central Bank of Turkey, 2015

indicator of convergence (or divergence). The null and alternative hypotheses take the following form:

Ho: $\alpha=0$ (unit root and non-stationary series)

$H a: \alpha<0$ (no unit root and stationary series)

In case, $\alpha=0$, there is evidence of a unit root process and no indication of stationary relative inflation rates. By contrast, $\alpha<0$ indicates evidence of no unit root and convergence of relative incomes to an equilibrium level.

In the LLC test, a different lag order for each region has been allowed. The lag order is represented by $\rho$. In our case, we determine it using three different measures from Akaike (1974), Schwarz (1978) and Hannan and Quinn (1979). We set the maximum possible time lag at 12 months.

The outcomes of the test are summarized in Table 3. The $\alpha$ value is negative and significant at $1 \%$ level 
in all regressions. This indicates strong and robust evidence of the rejection of the null hypothesis of a unit root. Therefore, it suggests the presence of a convergence pattern and declining differentials across regional inflation areas.

Table 3: Levin, Lin and Chu (2002), Panel Unit Root Test Results

\begin{tabular}{|l|c|c|}
\hline Lag Selection Criteria & $\alpha$ Value & P-Values \\
\hline Akaike & $-11.29^{* * *}$ & 0.000 \\
\hline Schwartz & $-15.68^{* * *}$ & 0.000 \\
\hline Hannan-Quinn & $-13.98^{* * *}$ & 0.000 \\
\hline
\end{tabular}

Note: Max. Lag=12 months, no intercept or trend, common unit root, eviews 6

Hence the declining disparities in inflation rates are confirmed both visually, through the graph of standard deviations and, inferentially, by panel unit root tests.

\subsection{Distribution Dynamics Analysis}

The distributional aspects of inflation help provide additional insights into the convergence process.

To be able to pursue such an analysis, we first need to organize our dataset by dividing the period of analysis into three sub-periods. These are the pre-crisis period of 2004-2007, the crisis period of 2008-2009, and the post-crisis period of 2010-2014. This type of division is relevant as the sub-periods cover different phases of the economic cycle during which the regions may show arbitrary price reactions to economic disturbances. Moreover, it also captures the effect of the economic crisis and related policy changes.

From a cross-sectional viewpoint, we divide the regions into 5 classes with respect to their annual average inflation rates. The regions which had the highest inflation rates are included in the first quintile, while those which experienced the lowest annual average inflation are included in the 5th quintile. The documentation of these quintiles is presented in Table 4 below.

Table 4: Regional inflation rates during different periods and quintiles

\begin{tabular}{|c|c|c|c|c|c|c|}
\hline Quintiles & Regions & $\begin{array}{l}\text { Pre-crisis, } \\
\text { 2004-2007 }\end{array}$ & Regions & $\begin{array}{c}\text { Crisis, } \\
\text { 2008-2009 }\end{array}$ & Regions & $\begin{array}{l}\text { Post-Crisis, } \\
2010-2014\end{array}$ \\
\hline \multirow[b]{5}{*}{ 1st Quintile } & TR42 & 9,48 & TRC2 & 9,12 & TRC1 & 7,77 \\
\hline & TR10 & 9,47 & TRB2 & 9,12 & TRA1 & 7,58 \\
\hline & TR22 & 9,14 & TRC1 & 8,90 & TRA2 & 7,53 \\
\hline & TR41 & 9,01 & TRB1 & 8,67 & TRC2 & 7,52 \\
\hline & TR32 & 8,99 & TR62 & 8,41 & TRB1 & 7,52 \\
\hline \multirow[b]{5}{*}{ 2nd Quintile } & TR31 & 8,98 & TR63 & 8,37 & TR71 & 7,45 \\
\hline & TR51 & 8,97 & TRC3 & 8,28 & TR21 & 7,33 \\
\hline & TR21 & 8,83 & TR90 & 8,23 & TR31 & 7,30 \\
\hline & TR62 & 8,75 & TR71 & 8,21 & TR22 & 7,29 \\
\hline & TR52 & 8,59 & TRA2 & 7,85 & TR51 & 7,27 \\
\hline \multirow[b]{5}{*}{ 3rd Quintile } & TR83 & 8,36 & TR51 & 7,83 & TR82 & 7,26 \\
\hline & TRA1 & 8,36 & TR72 & 7,53 & TR72 & 7,17 \\
\hline & TR72 & 8,29 & TR22 & 7,49 & TR90 & 7,17 \\
\hline & TR81 & 8,25 & TR21 & 7,35 & TRB2 & 7,15 \\
\hline & TRA2 & 8,19 & TR83 & 7,35 & TR62 & 7,13 \\
\hline \multirow[b]{5}{*}{ 4th Quintile } & TR61 & 8,12 & TR61 & 7,29 & TR81 & 7,12 \\
\hline & TR90 & 8,10 & TR10 & 7,22 & TR63 & 7,12 \\
\hline & TR71 & 8,06 & TRA1 & 7,15 & TR33 & 7,11 \\
\hline & TR33 & 8,06 & TR82 & 7,01 & TR83 & 7,09 \\
\hline & TRB2 & 8,02 & TR31 & 6,98 & TR10 & 7,03 \\
\hline \multirow[b]{6}{*}{ 5th Quintile } & TR63 & 8,00 & TR33 & 6,98 & TR52 & 6,98 \\
\hline & TR82 & 7,98 & TR52 & 6,93 & TR61 & 6,95 \\
\hline & TRC2 & 7,78 & TR42 & 6,92 & TR32 & 6,92 \\
\hline & TRC1 & 7,73 & TR32 & 6,89 & TR42 & 6,88 \\
\hline & TRB1 & 7,67 & TR41 & 6,73 & TR41 & 6,85 \\
\hline & TRC3 & 6,79 & TR81 & 6,45 & TRC3 & 6,79 \\
\hline
\end{tabular}


We then estimate the Kernel density functions of regional inflation rates for each period in order to understand the evolution of the shape of the regional inflation distribution. The results are shown in Figure 3

Figure 3: Kernel Density estimation of inflation rates, normal distribution assumed
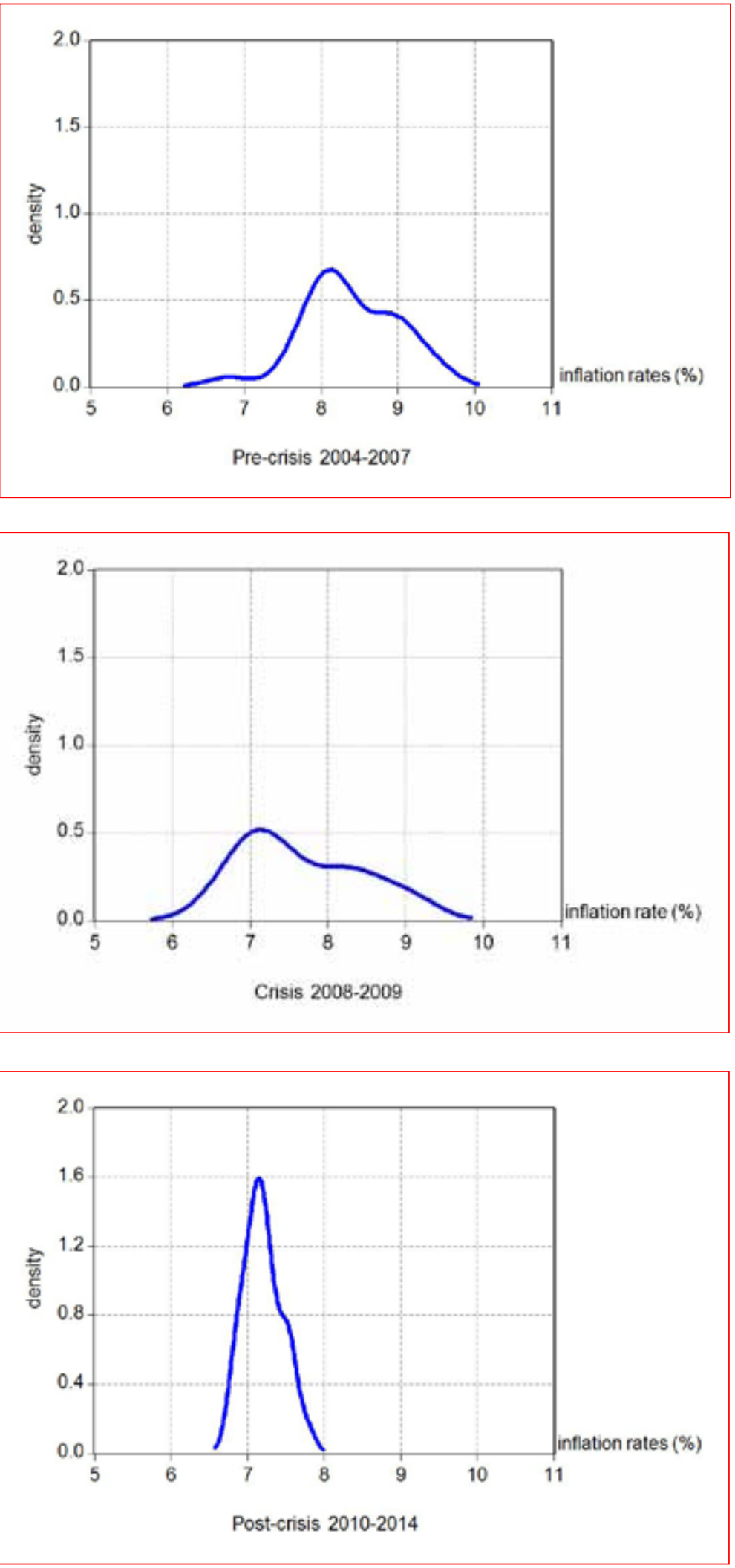

At a glance, during the first period, the probability mass is concentrated on two main modes. It therefore seems to be a bi-modal distribution. On the one hand, the highest probability mass is surrounded by about an $8 \%$ inflation rate as a first mode. On the other hand, the second mode is about a $9 \%$ rate, which is much less obvious compared to the first. During the second period, the shape of the distribution remains almost constant. The only difference is that the probability mass seems more uniform rather than bi-modal, and the probability mass has concentrated on $7 \%$ inflation rate instead of $8 \%$. Looking at these results, one may argue that national inflation rates seem to have declined during the crisis, while its regional distribution was not much affected. The decline in overall inflation during the recession seems plausible since unemployment tends to rise, while real wages and aggregate demand tend to decline. Therefore, prices increase at a slower rate since aggregate demand does not grow fast. In the last period, however, the results are quite different. During 2010-2014, the regional inflation rates have a very normally shaped distribution with much higher cross-regional homogeneity compared to previous years. This homogenization process points to a tendency towards decline in inflation disparities.

Another merit of this methodology is that it provides information on the intra-distributional mobility of regions. In other words, it helps in figuring out how mobile the regions are within the distribution. To understand this, we create Transition Markov Matrices by mapping regional inflation distribution in two consecutive periods (Asmussen, 2003). We calculate two matrices. The first shows the Transition Markov Matrix between the pre-crisis and crisis periods (in 5.1) and the second shows the Transition Markov Matrix between crisis and post-crisis periods (in 5.2).

Specifically, each value in these matrices shows the number of regions moving between two quintiles from the previous period to the current period. For instance, the value of " 3 " in Table 5.1 means that there are 3 regions that were in the 5 th quintile during the period of 2004-2007, and that they have moved to the 1 st quintile in the period of 2008-2009. The number of regions included in the diagonal indicates the degree of immobility, as those regions did not change their quintiles over those periods. 
In 5.1 , the immobility seems quite low. Only 2 regions out of 26 kept their relative position, while the rest of the 24 regions switched their quintiles between periods. In 5.2, 10 regions keep their quintile and 16 regions change.

Hence, one may argue that the relative position of regional inflation rates is far from a structural pattern. In contrast, relatively high and low inflationary places tend to change their quintiles frequently over time, indicating behavior that is random rather than structural.

The areas in Table 5 that are below the diagonal part (in blue) represent regions that moved to a better quintile (lower inflation), while the areas above the diagonal part (in orange) represent the regions which moved to a worse quintile (higher inflation). As 5.1 shows, 10 regions improved their quintiles, whereas 12 regions worsened. Similarly, as 5.2 shows, 9 regions improved their quintiles, whereas 6 regions worsened.

Overall, the distribution dynamics analyses indicate two main results. First, the distribution of regional inflation rates manifest a tendency to exhibit a unimodal and homogenous distribution form, which complements the convergence result found in panel unit root tests. Second, we have learned that within this distribution, the mobility of regions is quite high and that inflation behavior is not structural.

We think that the random dynamics of inflation found in our study is proof of a well-functioning market price system. Indeed, in none of the regions did we observe persistent and systematic high inflation. Recent policy changes have contributed to this process. From the mid-2000s onwards, the Turkish Central Bank has started to apply a direct inflation targeting policy, after which inflation rates have lowered, and price stability has been maintained both at the regional and national level. The flexible exchange rate policy adopted in 2001 was also influential in this process. The only negative side of this mechanism is that policies can hardly be designed as region-specific, as there is no systematic geographical pattern of inflation.

Table 5: Transition Markov Matrices

\begin{tabular}{|l|l|c|c|c|c|c|}
\hline & & & & Crisis & & \\
\hline & & 1st Quintile & 2nd Quintile & 3rd Quintile & 4th Quintile & 5th Quintile \\
\hline & $1^{\text {st }}$ Quintile & $\mathbf{0}$ & 0 & 1 & 1 & 3 \\
\hline & $2^{\text {nd }}$ Quintile & 1 & $\mathbf{0}$ & 2 & 1 & 1 \\
\hline Pre-crisis & $3^{\text {rd }}$ Quintile & 0 & 1 & $\mathbf{2}$ & 1 & 1 \\
\hline & $4^{\text {th }}$ Quintile & 1 & 2 & 0 & $\mathbf{1}$ & 1 \\
\hline & $5^{\text {th }}$ Quintile & 3 & 2 & 0 & 1 & $\mathbf{0}$ \\
\hline
\end{tabular}

(5.2)

\begin{tabular}{|c|l|c|c|c|c|c|}
\hline & & & & Post-Crisis & & \\
\hline & & 1st Quintile & 2nd Quintile & 3rd Quintile & 4th Quintile & 5th Quintile \\
\hline & $1^{\text {st }}$ Quintile & $\mathbf{3}$ & 0 & 2 & 0 & 0 \\
\hline & $2^{\text {nd }}$ Quintile & 1 & $\mathbf{1}$ & 1 & 1 & 1 \\
\hline Crisis & $3^{\text {rd }}$ Quintile & 0 & 3 & $\mathbf{1}$ & 1 & 0 \\
\hline & $4^{\text {th }}$ Quintile & 1 & 1 & 1 & $\mathbf{1}$ & 1 \\
\hline & $5^{\text {th }}$ Quintile & 0 & 0 & 0 & 2 & $\mathbf{4}$ \\
\hline
\end{tabular}




\section{CONCLUSIONS}

The current paper analyzed regional inflation convergence in Turkey over the period of 2004-2015 by adopting existing methodologies and a relatively new methodology. The outcomes of the research can be summarized in two parts.

First, inflation disparities have declined over time, especially during the post-crisis period after 2010. Hence, the overall price stabilization and disinflation process in Turkey has been coupled with inflation convergence across its regions. The inflation targeting policy has also contributed to this process (YIlmazkuday 2013). These results are confirmed using several methodologies, (i.e. SD graph, panel unit root tests and Kernel Density Estimates) and they seem consistent with the existing literature.

Second, in addition to the findings in the literature, we found that regions change their relative inflation rate positions quite often. This indicates that regional inflation behaviour is random in time and non-structural, as the relatively high and low inflationary places tend to change their quintiles frequently. Similarly, geographical randomness is also verified using Moran I's test.

All these results imply several policy suggestions. First, achieving inflation convergence is a harder task than initially understood, as it seems to be random behavior. The economic drivers behind this should be carefully analyzed by policy makers. Second, trade integration should be promoted so as to make regional prices converge with each other. Finally, during possible recessions in the future, in addition to targeting aggregate disinflation, regional dispersion should be addressed with great care as it is critical to Central Bank policy success.

\section{REFERENCES}

Akaike, H. 1974. A new look at the statistical model identification. IEEE Transactions on Automatic Control 19 (6): 716-723.

Akdi, Y. and Sahin, A. 2007. Enflasyon yakınsaması: Türkiye Örnegi. Finans Politik ve Ekonomik Yorumlar 44 (514): 69-74.

Asmussen, S. R. 2003. Markov chains. Applied probability and queues. Stochastic Modelling and Applied Probability 51: 3-8.

Balassa, B. 1964. The purchasing power parity doctrine: a reappraisal. Journal of Political Economy 72 (6): 584-596.

Barro, R. J. and Sala-i-Martin, X. 1992. Convergence. Journal of Political Economy 100 (2): 223-51.
Barth, J. R. and Bennett, J. T. 1975. Cost-push versus demand-pull Inflation: some empirical evidence. Journal of Money, Credit \& Banking 7 (3): 391-397.

Baumol, W. and Bowen, W. 1966. Performing arts: the economic dilemma. New York: 20th Century Fund.

Beck, G. W. and Weber, A. A. 2001. How wide are European borders? On the integration effects of monetary unions. CFS Working Paper No. 2001/07. https://www.ifkcfs.de/ fileadmin/downloads/publications/wp/01_07_revised. pdf (accessed 12th September, 2015)

Beck, G. W., Hubrich, K. and Marcellino, M. 2006. Regional inflation dynamics within and across Euro Area countries and a comparison with the US. ECB Working Paper No. 681. https://www.ecb.europa.eu/pub/pdf/scpwps/ ecbwp681.pdf?819a97bbbcaa5b6b48dac1f731eaba67 (accessed 12th September, 2015)

Becker, S. S. 2011. What drives the relationship between inflation and price dispersion? Market power vs. price rigidity. SFB 649 Discussion Paper 2011-019. http://sfb649. wiwi.hu-berlin.de/papers/pdf/SFB649DP2011-019.pdf (accessed 12th September, 2015)

Breitung, J. and Das, S. 2003. Panel unit root tests under cross sectional dependence. Mimeo: University of Bonn. https://www.cass.city.ac.uk/data/assets/pdf_ file/0005/65237/absBreitungDas.pdf (accessed 12th September, 2015)

Breitung, J. 2000. The local power of some unit root tests for panel data. In Nonstationary panels, panel cointegration, and dynamic panels, edited by B. H. Baltagi, Book series: Advances in econometrics 15: 161-178.

Busetti, F., Forni, L., Harvey, A. and Venditti, F. 2007. Inflation convergence and divergence with the European Monetary Union. International Journal of Central Banking 3 (2): 95-121.

Cechetti, S. G., Mark, N. C. and Sonora R. J. 2002. Price index convergence among United States cities. International Economic Review 43 (4): 1081-1099.

Chang, Y. 2002. Nonlinear IV unit root tests in panels with cross-sectional dependency. Journal of Econometrics 110 (2): 261-292.

Chang, Y. 2004. Bootstrap unit root tests in panels with cross-sectional dependency. Journal of Econometrics 120 (2): 263-293.

Dickey, D. A. and Fuller, W. A. 1979. Distribution of the estimators for autoregressive time series with a unit root. Journal of the American Statistical Association 74 (366): 427-431.

Gezici, F. and Hewings, G. J. D. 2007. Spatial analysis of regional inequalities in Turkey. European Planning Studies 15 (3): 383-403.

Hannan, E. J. and Quinn, B. G. 1979. The Determination of the order of an autoregression. Journal of the Royal Statistical Society Series B 41 (2): 190-195. 
Holmes, M. J. 2002. Panel data evidence on inflation convergence in the European Union. Applied Economics Letters 9 (3): 155-158.

Im, K. S., Pesaran, M. H. and Shin, S. Y. 2003. Testing for unit roots in heterogeneous panels. Journal of Econometrics 115 (1): 53-74.

Kocenda, E. and Papell, D. H. 1997. Inflation convergence within the European Union: a panel data analysis. International Journal of Finance and Economics 2 (3): 189-198.

Levin, A., Lin, C. and Chu, C. J. 2002. Unit root tests in panel data: asymptotic and finite-sample properties. Journal of Econometrics 108 (1): 1-24.

Magrini, S. 2009. Why should we analyse convergence using the distribution dynamics approach? Scienze Regionali 8 (1): 5-34.

Mentz, M. and Sebastian, S. P. 2003. Inflation convergence after the introduction of the Euro. CFS Working Paper No. 2003/30. https://www.ifk-cfs.de/fileadmin/downloads/publications/wp/03_30_new.pdf, (accessed 12th September, 2015)

Mihaljek, D. and Klau, M. 2004. The Balassa-Samuelson effect in Central Europe: a disaggregated analysis. Comparative Economic Studies 46 (1): 63-94.

Mihaljek, D. and Klau, M. 2008. Catching-up and inflation in transition economies: the Balassa-Samuelson effect revisited. BIS Working Papers 270, Bank for International Settlements. http://www.bis.org/publ/work270.pdf, (accessed 12th September, 2015)

Moran, P. A. P. 1950. Notes on continuous stochastic phenomena. Biometrika 37 (1/2): 17-23.

Pesaran, M. H. 2007. A pair-wise approach for testing output and growth convergence. Journal of Econometrics 138 (1): 312-355.

Rey, S. and Montouri, B. 1999. US regional income convergence: a spatial econometric perspective. Regional Studies 33 (2): 143-156.

Rey, S. 2001. Spatial analysis of regional income inequality. Regional economics applications laboratory. University of Illinois. http://econwpa.repec.org/eps/urb/papers/0110/0110002.pdf (accessed 12th September, 2015)

Rogers, J. H., Hufbouer, G. C., and Wada, E. 2001. Price level convergence and inflation in Europe. Peterson Institute for International Economics Working Papers, No: 01-1,Washington.http://www.iie.com/publications/ wp/01-1.pdf, (accessed 12th September, 2015)

Rogers, J. 2007. Monetary union, price level convergence, and inflation: how close is Europe to the USA?. Journal of Monetary Economics 54 (3): 785-796.
Samuelson, P. A. 1964. Theoretical notes on trade problems. Review of Economics and Statistics 46 (2): 145-154.

Schwarz, G. 1978. Estimating the dimension of a model. Annals of Statistics 6 (2): 461-464.

Siklos, P. L. and Wohar, M. E. 1997. Convergence in interest rates and inflation rates across countries and over time. Review of International Economics 5 (1): 129-141.

Solow R.M. 1956. A contribution to the theory of economic growth. The Quarterly Journal of Economics 70 (1): 65-94.

Quah D. 1993a. Empirical cross-section dynamics in economic growth. European Economic Review 37 (2-3): 426-434.

Quah, D. 1993b. Galton's fallacy and tests of the convergence hypothesis. Scandinavian Journal of Economics 95 (4): 427-443.

Weber, A. A. and Beck, G. W. 2005. Inflation rate dispersion and convergence in monetary and economic unions: lessons for the ECB. CFS Working Paper No. 2005/31 https://www.ifk-cfs.de/fileadmin/downloads/publications/ wp/05_31.pdf (accessed 12th September, 2015)

Weber, A. A. 2004. European inflation dynamics and inflation convergence, open macro models and policy in the development of European Economy. Paper Presented at Conference at the European University Institute, 15 October, Florence.

Weyerstrass, K., Aarle, B., Kappler, M. and Seymen, A. 2011. Business cycle synchronisation with(in) the Euro Area: in search of a 'Euro Effect'. Open Economies Review 22 (3): 427-446.

Tunay, B. K. and Silpagar, A. M. 2007. Dinamik Mekan-Zaman Panel Veri Modelleriyle Türkiye'de Bölgesel Enflasyon Yakınsamasının Analizi. Gazi Üniversitesi İktisadi ve İdari Bilimler Fakültesi Dergisi 9 (1):1-27.

Yeşilyurt, F. and Elhorst, P. 2014. A regional analysis of inflation dynamics in Turkey. Annals of Regional Science (52): $1-17$

Yeşilyurt, F. 2014. Bölgesel Enflasyon Yakınsaması: Türkiye Örneği. Ege Akademic Review 14 (2): 305-314

Yılmazkuday, H. 2013. Inflation targeting, flexible exchange rates and inflation convergence. Applied Economics 45 (5): 593-603.

Yıldırım J., Öcal N. and Özyildirim S. 2009. Income inequality and economic convergence in Turkey: A spatial effect analysis. International Regional Science Review 32 (2): 221-254

Zivot, E. ve Andrews, D. W. K. 1992. Further evidence on the great crash, the oil- price shock, and the unit-root hypothesis. Journal of Business and Economic Statistics 10 (3): 251-270. 